\title{
Duration, timing and order: How housing histories relate to later life wellbeing
}

\author{
Bram Vanhoutte University of Manchester, UK \\ Morten Wahrendorf University of Düsseldorf, Germany \\ James Nazroo University of Manchester, UK
}

(Received January 2017

Revised April 2017)

http://dx.doi.org/10.14301/llcs.v8i3.445

\begin{abstract}
Accumulation, critical period and social mobility are three powerful, interrelated life course mechanisms often tested using relatively crude empirical measures. This contribution wants to highlight the possibilities of life history data in grasping the importance of duration, timing and order of housing over the life course, by examining its association with wellbeing in later life. Housing is a key dimension of life course socioeconomic position, as the most common form of wealth accumulation in the UK. Our study makes use of the residential life history data, from birth up until the age of 50, collected in wave 3 of the English Longitudinal Study of Ageing (ELSA), in a combination of sequence analysis, cluster analysis and regression techniques. A longer duration of renting and owning accommodation is related to respectively worse and better later life affective and eudemonic wellbeing. Moving more in childhood is not associated with later life wellbeing, while frequent moving in young adulthood has a positive association with affective and eudemonic wellbeing. Moving more in midlife is associated with lower life satisfaction. Ten distinct housing careers emerge, illustrating the importance of accommodating heterogeneity in the population. Downward housing trajectories are associated with significantly lower later life wellbeing, while growing up abroad as a child is associated with higher later life wellbeing.
\end{abstract}

\section{Keywords}

Life course, housing, life history data, sequence analysis, United Kingdom

\section{Introduction}

The life course perspective acknowledges the linkage between personal and historical chronologies, so that contextualised insights into how events and outcomes are related can emerge (Abbott, 2001; Elder, Johnson, \& Crosnoe, 2003). In particular, the conceptual frameworks used to examine how personal history affects health and wellbeing, critical periods, accumulation and social mobility, have been shown to be powerful explanations for the relationship between location in the social hierarchy and various health outcomes (Ben-shlomo \& Kuh, 2002; Kendig \& Nazroo, 2016).
The maturation of analytical techniques and data to examine life histories in more detail urges a refining of these conceptual mechanisms, each emphasising a different way in which time influences our lives. This paper illustrates how duration, timing and ordering can be used as empirical translations of the concepts of respective accumulation, critical periods and mobility (Vanhoutte \& Nazroo, 2016b; Wahrendorf \& Chandola, 2016) in the context of accommodation histories in the UK.

Accommodation histories, or the sequence of dwellings occupied throughout a lifetime are a 
relevant starting point to examine life course influences (Stovel \& Bolan, 2004). Where and how people live reflects their current social position (Savage et al., 2013), as well as social origins and life trajectories (Feijten \& Mulder, 2002). Furthermore, studying housing has some additional benefits, over other indicators of socioeconomic position such as occupation or education. While not everyone has an occupation, and education is accomplished for most people by early adulthood, everyone has a place of residence throughout her or his life. In addition, owning a property is the most common, and typically largest, form of financial investment, especially in the UK context (Banks, Blundell, \& Smith, 2012).

\section{Housing careers: Housing and life course}

The housing career, or the succession of dwellings occupied by individuals over their lives (Kendig, 1990), has been examined in the context of life course studies in two main ways: either by examining the link between housing careers and other life domains (Clark, Deurloo, \& Dieleman, 1994, 2003a; Feijten \& Mulder, 2002) or the influence of societal context on housing trajectories (Clark et al., 1994; Kendig, 1990). Rather than deepening existing knowledge of housing careers themselves, this paper proposes a wider view of the long term associations of housing by addressing two issues: the implicit assumption of eventual homeownership, and the restriction on housing careers in private dwellings in one country.

Tenure change, and especially the move from renting to owning, is seen as the key event of the housing career in most housing research (Kendig, 1990; Mulder \& Wagner, 1998). Although we do not dispute this, the primary focus on this specific transition blurs the fact that a substantial, and increasing, part of the population never acquires their own home (Lupton et al., 2009). The experiences of current younger generations in the UK illustrate this clearly: more and more people are unable to afford to buy a home, and either move back into their parental homes or rent for extended periods of time from private landowners (Dorling, 2015; Lupton, 2016). This change in housing careers for younger compared with older generations underwrites the need for a broader view on housing careers, examining the long term correlates of more varied and flexible trajectories, without home ownership as a normative endpoint.
A second limitation we want to address is to include more diversity in the type of housing considered. Alongside renting or owning, a number of non-private forms of residence exist. These other forms of accommodation, such as orphanages, boarding schools, and army accommodation, are often tied to a specific life phase, and can tell us more about a person's life course. A second form of dwelling diversity is tied in with international migration, and the aftermath of UK's colonial history. In the bulk of housing studies, only accommodation inside one country is examined, although a significant part of the population lived abroad for at least a part of their life. While these limitations often arise from pragmatic and datarelated considerations, they influence results and policy conclusions, and as such narrow the view on housing and how it reflects other life domains at particular life stages.

This paper examines the correlates of housing through the prism of the life course mechanisms of accumulation, critical period and social mobility. Rather than seeing the sequences and events that make up housing careers as outcomes, we examine to what extent housing careers can be used to trace social differences over the life course and the associations of these differences with wellbeing in later life. Reflecting the different conceptions of time in life course studies, we give an overview of previous research on housing careers through the lens of duration, timing and ordering (Vanhoutte \& Nazroo, 2016b; Wahrendorf \& Chandola, 2016). Widening rather than deepening the understanding of housing careers from a life course perspective, we want to incorporate forms of housing that do not fit the renting/owning dichotomy, such as nonprivate dwellings and living abroad.

\section{Duration, or accumulation of risk exposure}

A commonly studied life course mechanism relevant to the possible influence of housing careers is accumulation. In the logic of cumulative (dis)advantage, inequalities are expressed over time, not instantaneously (Dannefer, 2003). Small differences at one point can grow over time and develop into large disparities in health, wealth and wellbeing (Vanhoutte \& Nazroo, 2016a). Therefore accurately capturing the duration of exposure to potentially damaging (or protective) environments is an essential step. It allows investigation of the extent to which a response-type relationship exists 
between the stressor over the life course and the outcome under study.

In the context of accumulative exposure, we believe type of tenure is a primary indicator. Housing quality is a reliable proxy for exposure to health risks and socioeconomic position. Housing conditions mark risk exposure to environmental stressors, such as toxins, pollutants, noise and crowding, while at the neighbourhood level there are further differences in ambient conditions in the form of traffic, availability of green or blue space, presence of municipal services and the type of food provisions. These are all part of the causal chain that links socioeconomic circumstances with health outcomes (Ellaway \& Macintyre, 1998; Evans \& Kantrowitz, 2002; Windle, Burholt, \& Edwards, 2006). As renters and owners occupy different kinds of dwellings (Rossi \& Weber, 1996), ownership has effects on health and wellbeing over and above the material wealth it represents, through this exposure to health hazards in the dwelling or its immediate environment (Ellaway \& Macintyre, 1998; Macintyre et al., 2003). Lower housing quality of rented accommodation as such contributes to worse mental health (Hopton \& Hunt, 1996) A final point is that owning a house can contribute to a higher feeling of ontological security, and deliver less tangible psycho-social benefits (Hiscock, Kearns, Maclntyre, \& Ellaway, 2001).

\section{Timing, or critical period}

Closely interlinked with the idea of duration is the idea of timing. The point at which an event happens can be crucial for the impact it has, an idea that lies at the base of the concept of critical period, and most research on scarring early life effects (Ben-shlomo \& Kuh, 2002). Next to the event itself, unfavourable timing can set in motion a whole cascade of knock-on effects that negatively influence the outcome.

In a housing career, moving house and the circumstances this reflects is the most typical event that would come to mind. The timing of the transition from renter to owner is often seen as the key moment of the housing career, and as such has been researched intensively (Clark et al., 1994; Clark, Deurloo, \& Dieleman, 2003b; Mulder \& Wagner, 1998). Here we emphasise the more general influence of the timing of moving house in the life course.

Moving as a single event can have positive, neutral and negative effects, mainly because of the transitions that provoke or accompany it (Gambaro \& Joshi, 2016). It is a stressful event in itself, and in addition potentially disrupts place attachment and social embeddedness, two factors related to higher wellbeing especially for low-income families (Manzo, Kleit, \& Couch, 2008). Moving house is often motivated by positive life events and is related to an improvement in housing quality, and has been shown to have a small positive effect on housing satisfaction, but no tangible effect on life satisfaction (Nakazato, Schimmack, \& Oishi, 2011).

However, moving house frequently reflects instability or even housing insecurity, which inhibits building up meaningful close friendships and can potentially be damaging for children (Evans, Wells, \& Moch, 2003; Oishi \& Schimmack, 2010). At the same time, some important life course events, such as attending tertiary education, forming or ending a partnership, and having children, relate to moving house (Clark et al., 1994), so that in some phases of the life cycle moving will occur more frequently than in others (Clark \& Onaka, 1983). The absence of moves in these busy life phases, such as early adulthood, can have negative implications later in life.

\section{Ordering, or social mobility}

A contextualised and holistic approach to the life course places events and spells in a sequential order, instead of considering them as isolated (Abbott, 1995; Aisenbrey \& Fasang, 2010). Knowing what happened before and after an event can guide our understanding of the variation in life courses, and in this way allows a consideration of dynamic and diverse life course trajectories.

As housing can be considered a marker of socioeconomic position, housing careers become a means to study social mobility. Earlier studies on social mobility in England have illustrated that although stability is by far the most common life course trajectory, upward and downward mobility do occur, and have consequences for later life health and wellbeing (Blane, Harding, \& Rosato, 1999; Niedzwiedz, Katikireddi, Pell, \& Mitchell, 2012; Vanhoutte \& Nazroo, 2016a). The influence of housing careers on later life wellbeing should be considered in the context of the typical upward trajectory to home ownership, with an upward trend in terms of quality, price and tenure (Clark et al., 2003a) which represents social norms about housing careers. A frustration of this norm may reflect a lack of either financial resources, or 
missing out on life course events such as forming a partnership, or having children, both of which can have a negative impact on later life wellbeing.

\section{Later life wellbeing}

We investigate the relevance of these aspects of housing careers for later life wellbeing, a common outcome in the broader framework of successful ageing (Hildon, Smith, Netuveli, \& Blane, 2008; Stone, Evandrou, \& Falkingham, 2013). Wellbeing is multidimensional in nature and comprises three different, empirically identifiable, conceptions: affective, cognitive and eudemonic, respectively reflecting happiness, satisfaction and selfactualisation (Vanhoutte, 2014). Distinguishing multiple forms of wellbeing is useful as each type of wellbeing has its own dynamic, is produced by different sets of resources (Jivraj, Nazroo, Vanhoutte, \& Chandola, 2014), and relates in an idiosyncratic way to different life course mechanisms (Vanhoutte \& Nazroo, 2016a). The affective aspect of wellbeing consists of moods and emotions, (Diener, Suh, \& Lucas, 1999), of which depressive symptoms (CES-D, (Radloff, 1977)) capture the negative side of the spectrum (Wood, Taylor, \& Joseph, 2010). Childhood adversities have shown to matter more for later life affective wellbeing (Kessler, 1997), as the way we respond to stress is thought to be embedded in our formative years. Cognitive wellbeing, or life satisfaction, is a judgemental process in which individuals asses the quality of their life based on their own criteria (Pavot \& Diener, 1993). Life satisfaction in old age is more closely related to later stages of the life course, as our judgement tends to be driven by what we experienced recently (Kahneman \& Krueger, 2006).. Eudemonic wellbeing, or the degree of control, autonomy and self-realisation (Ryff \& Keyes, 1995) is related more strongly to accumulative (dis)advantages across the life course (Blane, Higgs, Hyde, \& Wiggins, 2004; Vanhoutte \& Nazroo, 2016a).

\section{Hypotheses}

Spending a longer part of the housing career in rented accommodation is associated with in lower wellbeing, and inversely longer durations of homeownership are associated with higher wellbeing in later life.

Moving house in childhood and midlife are negatively associated with wellbeing, but moving in young adulthood is positively associated.
Movements from owning to renting will have a negative association with later life wellbeing.

\section{Data and methods}

\section{Data}

We use the retrospective life history data of the English Longitudinal Study of Ageing (ELSA) (Marmot et al., 2017), collected in wave 3 (2007) (Ward, Medina, Mo, \& Cox, 2009). ELSA is a panel study of people aged 50 or older living in private households in England, with a sample that was drawn from households previously responding to the Health Survey for England between 1997 and 2004. The sample was refreshed in wave 3 to maintain representation of people aged 50-53, yielding a total of 9,771 participants of which 7,855 provided life history information (Steptoe, Breeze, Banks, \& Nazroo, 2013). Of these respondents, $56 \%$ are aged between 50 and 65 , reaching the age of 15 between 1957 and 1972.

The event history calendar (Axinn, Pearce, \& Ghimire, 1999; Freedman, Thronton, Camburn, Alwin, \& Young-DeMarco, 1988), which uses visual aids, enquires about streams of events, records event sequences, and contextualises questions about various life events was used to collect retrospective information on several domains (e.g. work, relationships and housing). This data collection tool is more reliable than standard survey approaches for complex autobiographical data (Belli, 1998), yields higher response rates (Belli, 1998), and is adaptable to other modes of information gathering (Kendig et al., 2014). Following its use in ELSA, the event history calendar has been used in several other studies, such as the Survey of Health, Ageing and Retirement in Europe (SHARE) (Schröder, 2011), the Australian Life Histories and Health (LHH) study (Kendig et al., 2014) and the US Health and Retirement Study (HRS).

The life history data used in this paper are accommodation histories. They allow for a description of the accommodation situation for each year of age from birth up until the age of 50 . We distinguish between four different states: respondents can describe themselves as living in rented, owned, or non-private accommodation, or abroad. Figure 1 is a chronogram of the accommodation histories, which shows the proportion in each state for each year of age. Owning and renting are the most common 
categories of accommodation, while residing in other, non-private forms of accommodation (armed forces, accommodation tied to employment, boarding school, or children's home, hospital, etc.) and living abroad are relevant markers for specific life phases or life courses, each occurring for at least one year in about $20 \%$ of our sample. Over the life course, there is an expansion of occupying owned housing, and a decrease in rented housing. In the period between the age of 15 and 20 there is a marked, but temporary, increase of non-private dwelling (5\%) and living abroad (about 2 percent).
We limit our analysis of accommodation histories from birth to the age of 50, not to lose respondents by age censoring. Due to inaccuracies in reporting, some gaps between housing spells occurred, which we imputed using multiple imputation for categorical time series (MICT) in Stata (Halpin, 2015), a technique specifically developed for this type of data. This form of imputation informed by the state prior and/or after the gap, increased the sample from 6,848 to 7,505 cases. To account for selectivity of respondents to the life history data, we used the weighting provided (Ward et al., 2009).

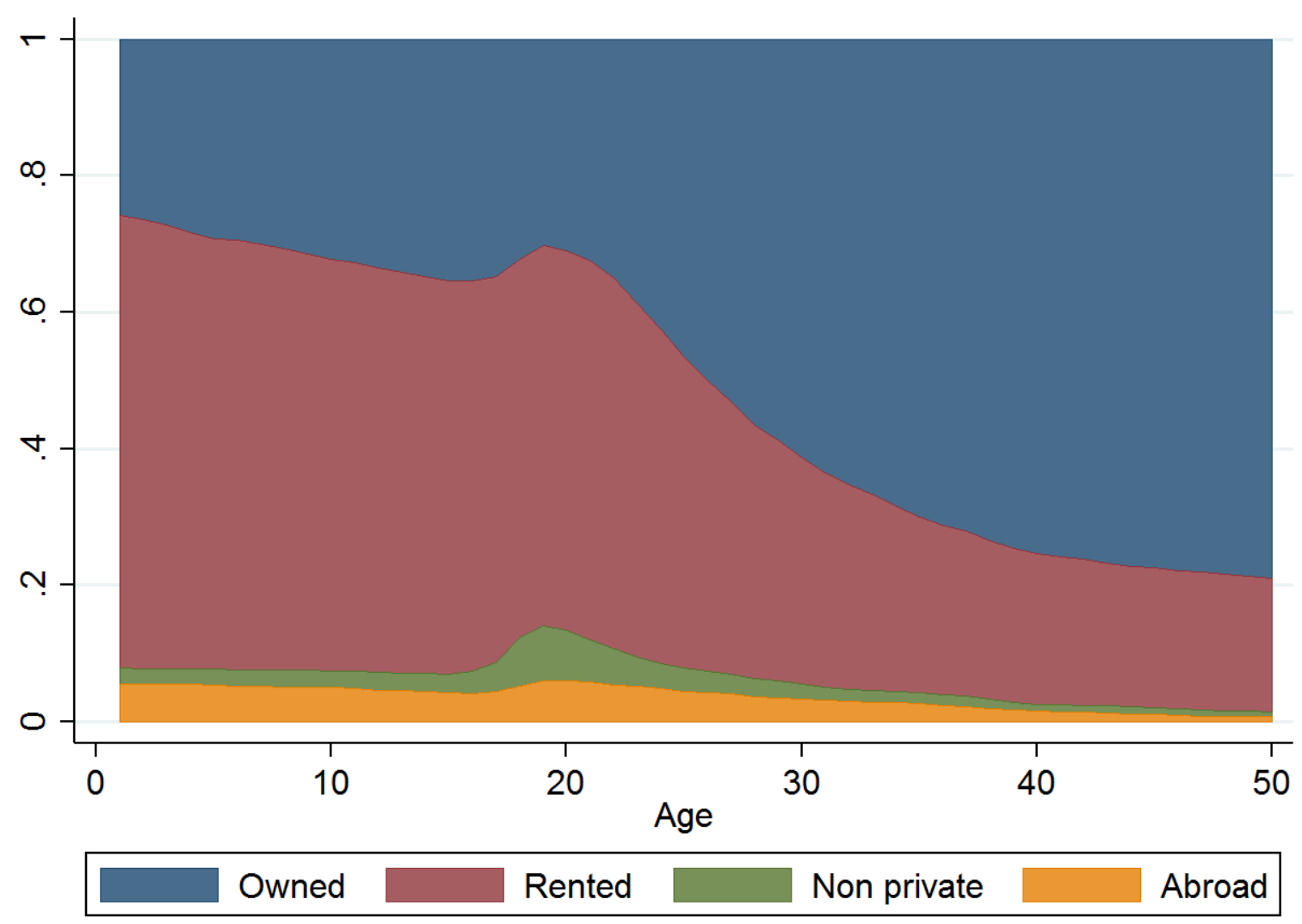

Figure 1: Chronogram of accommodation states over age $(n=7505)$

Table 1. Descriptive statistics of dependant variables

\begin{tabular}{lccccc}
\hline & $\mathbf{N}$ & Mean & Std. Dev. & Min & Max \\
\hline CESD & 7,432 & 1.46 & 1.93 & 0 & 8 \\
SWLS & 6,475 & 24.96 & 6.50 & 5 & 35 \\
CASP & 6,347 & 34.07 & 6.95 & 4 & 45 \\
& & & & & \\
\hline
\end{tabular}




\section{Dependant variables}

The eight item CES-D scale, with binary yes or no answering categories is used as a measure of low affective wellbeing. The satisfaction with life scale (SWLS) (Diener, Emmons, Larsen, \& Griffin, 1985), used as a measure of cognitive wellbeing, consist of five items and is answered using a five point likert scale ranging from totally agree to totally disagree. To gauge eudemonic wellbeing the adapted 15 item Control, Autonomy, Self-Actualisation and Pleasure (CASP) scale (Hyde, Wiggins, Higgs, \& Blane, 2003; Vanhoutte, 2014) is used, which has better measurement properties and theoretical justification than the original 19 item version, with four answering categories varying in frequency. Except for affective wellbeing (CES-D), our wellbeing measures where part of the selfcompletion questionnaire.

\section{Control variables}

We adjust for a number of current sociodemographic characteristics (Table 2) (age, gender and ethnicity), health status (limitations in instrumental activities of daily living), and marital status, each of which has an established influence on subjective wellbeing in later life (Jivraj et al., 2014).

Table 2. Descriptive statistics of control variables

\begin{tabular}{|c|c|c|c|c|c|}
\hline & $\mathbf{N}$ & $\begin{array}{c}\text { Mean/ } \\
\text { Proportion }\end{array}$ & Std. Dev. & Min & Max \\
\hline $\begin{array}{l}\text { Age } \\
\text { Gender } \\
\text { (ref.: Female) }\end{array}$ & 7486 & 65.04 & 10.27 & 49 & 91 \\
\hline $\begin{array}{l}\text { Ethnicity } \\
\text { (ref.: White) }\end{array}$ & 7486 & $44 \%$ & & & \\
\hline $\begin{array}{l}\text { Non-White } \\
\text { Limitations in instrumental } \\
\text { activities daily living } \\
\text { (ref.: At least one) }\end{array}$ & 7486 & $2 \%$ & & & \\
\hline $\begin{array}{l}\text { Marital status } \\
\text { (ref.: Never married) } \\
\text { Widowed, divorced or } \\
\text { separated }\end{array}$ & 7486 & $25 \%$ & & & \\
\hline Married or cohabiting & 7486 & $70 \%$ & & & \\
\hline
\end{tabular}

\section{Methods}

Our analysis consists of examining the individual housing careers using sequence analysis (Abbott, 1995; Aisenbrey \& Fasang, 2010). Sequence analysis is a group of research methods taking a holistic approach by focusing on trajectories more than transitions, recently gaining impetus by range of new methodological developments in response to life course applications.

Although the main idea of sequence analysis is to study whole sequences, and as such investigate duration, timing and order together, this paper separates them out to highlight some simple but valuable metrics that can be derived from life history data. Using these different ways of looking at sequences can get us closer to the three conceptual aspects of the life courses we are studying. All calculations and figures were done with Stata using the 'sadi' package (Halpin, 2014) and the 'sq' package (Brzinsky-Fay, Kohler, \& Luniak, 2006). 


\section{Duration}

A straightforward way of examining accommodation histories is capturing the total time spent in a state. Cumulative duration in a state as such only reflects this passage of time, and does not take into account house moves or other aspects of a housing career. Table 3 illustrates on average our cohort spent their first 50 years by renting about 22 years, owning a house for 25 years, living abroad for almost two years and living in non-private dwellings for about one year. There is a large variation in how long people spent renting and owning, as well as substantial variation in the duration of living abroad.

\section{Timing over the life course}

We are equally interested in examining if similar events, i.e. moving frequently, have a differential influence on later life depending on which life phase they occurred. For this purpose, we delineate three life phases, based on figure 1: early life (1-18), young adulthood (19-29) and midlife (30-50), and calculate metrics specific for each life phase (Table 3).
A simple way of thinking about housing instability is the number of changes in accommodation, or the number of moves. Using the number of moves by life phase does not distinguish if a person is moving to the same type of accommodation or not. Table 3 shows that on average, people move more in the young adult phase than in early life or midlife.

Moving between different types of accommodation is captured by Shannon's entropy. Shannon's entropy is a measure for the complexity of a sequence, based on the cumulative duration in each state. It does not take into account the number of moves, but only time spent in different states.

By multiplying Shannon's entropy with the number of housing spells divided by the total length of time, we distinguish between different states, and incorporate the number of house moves, which gives us a value for the instability of the housing career, with a value between 0 (very stable) and 1 (very instable).

Table 3. Descriptives of metrics derived from sequences $(\mathrm{N}=7505)$ (weighted)

\begin{tabular}{|c|c|c|c|c|}
\hline & Mean & SD & Min & Max \\
\hline \multicolumn{5}{|l|}{ Cumulative Duration } \\
\hline Ownership & 24.64 & 15.59 & 0 & 50 \\
\hline Renting & 22.13 & 15.78 & 0 & 50 \\
\hline Non-private & 1.27 & 4.04 & 0 & 50 \\
\hline Abroad & 1.96 & 6.07 & 0 & 50 \\
\hline \multicolumn{5}{|l|}{ Number of moves } \\
\hline Childhood & 1.53 & 0.89 & 1 & 8 \\
\hline Young adult & 2.02 & 1.10 & 1 & 9 \\
\hline Midlife & 1.46 & 0.86 & 1 & 8 \\
\hline \multicolumn{5}{|l|}{ Entropy } \\
\hline Childhood & 0.25 & 0.40 & 0 & 1.97 \\
\hline Young Adult & 0.56 & 0.50 & 0 & 1.96 \\
\hline Midlife & 0.22 & 0.38 & 0 & 1.94 \\
\hline \multicolumn{5}{|l|}{ Instability } \\
\hline Childhood & 0.04 & 0.07 & 0 & 0.79 \\
\hline Young adult & 0.08 & 0.10 & 0 & 0.95 \\
\hline Midlife & 0.02 & 0.04 & 0 & 0.52 \\
\hline
\end{tabular}




\section{Ordering}

To group whole sequences, we use dynamic hamming (Lesnard, 2006), an extension to optimal matching (OM) analysis (Abbott, 1995; Aisenbrey \& Fasang, 2010). Both techniques compare sequences and quantify their differences (or "distances"). In line with our theoretical focus on ordering, we use the dynamic hamming procedure (Lesnard, 2006). This method is a data informed way of calculating substitution costs, by taking into account how common a transition is at each time point. In a second step, the resulting distance matrix can be used in cluster analysis to identify empirically homogeneous groups, with similar sequences. At this point, we used Ward's linkage to determine the most appropriate number of clusters, based on commonly used measures of cluster quality (Halpin, 2016). Findings favour either three, eleven or twelve clusters (Table 4). We considered the three best solutions for each measure of cluster quality. We opted for the ten cluster solution as it was ranked second best for two separate measures, as well as making substantive sense.

Table 4. Cluster stopping rules for 2-15 cluster solutions

\begin{tabular}{lllr}
\hline $\begin{array}{l}\text { Number } \\
\text { of } \\
\text { clusters }\end{array}$ & Calinski Harabasz pseudo F & Duda-Hart Je(2)/Je(1) & Duda-Hart pseudo T squared \\
\hline 2 & 2523.81 & 0.6365 & 2642.09 \\
3 & $\mathbf{2 7 7 4 . 2 8}$ & 0.8226 & 620.00 \\
4 & 2246.48 & 0.8480 & 582.75 \\
5 & 1931.21 & 0.8338 & 521.05 \\
6 & 1758.84 & 0.6760 & 658.42 \\
7 & 1625.96 & 0.8626 & 294.31 \\
8 & 1514.66 & 0.7185 & 523.33 \\
9 & 1409.59 & 0.8394 & 178.54 \\
10 & 1325.42 & $\mathbf{0 . 8 7 2 4}$ & $\mathbf{7 4 . 4 5}$ \\
11 & 1242.01 & $\mathbf{0 . 8 8 0 1}$ & 228.67 \\
12 & 1175.50 & 0.8656 & $\mathbf{5 0 . 0 0}$ \\
13 & 1108.25 & 0.7596 & 343.68 \\
14 & 1050.52 & 0.8555 & 236.73 \\
15 & 1001.80 & $\mathbf{0 . 8 6 7 9}$ & $\mathbf{1 0 4 . 2 5}$ \\
\hline
\end{tabular}

One descriptive way to represent these clusters is through a modalplot, representing the "medoid sequence", or sequence closest to the cluster centre (see Figure 2) (Brzinsky-Fay et al., 2006). In this graphical representation the modal category for each age year is plotted, so that an impression of the modal sequence in each cluster emerges. A white gap, such as in the last cluster denotes equal probability of two states, in this case living in rented or owned accommodation. We present the clusters according to the age at which respondents first lived in an owned home. Two clusters have a homogenous pattern of occupying either rented (14.5\%) or owned homes (22.4\%), and together capture more than a third of respondents. Four clusters illustrate a similar pattern of transition, from living in a rented home to an owned home, at respectively the age of $10(9.2 \%), 22(18.7 \%), 28$ $(10.6 \%)$ and 32 (7.2\%). The remaining four clusters, comprising about a fifth of the cases, have widely different housing careers. A more mixed profile shows an alternation between rented and owned housing in adulthood (6.8\%). One cluster illustrates a transition from growing up in an owned house to a life of renting starting at age 20 (3.8\%). Two clusters illustrate the relatively fast transition to living in an owned home of those growing up abroad and coming back as a child (3.3\%) or as an adult (3.5\%). 


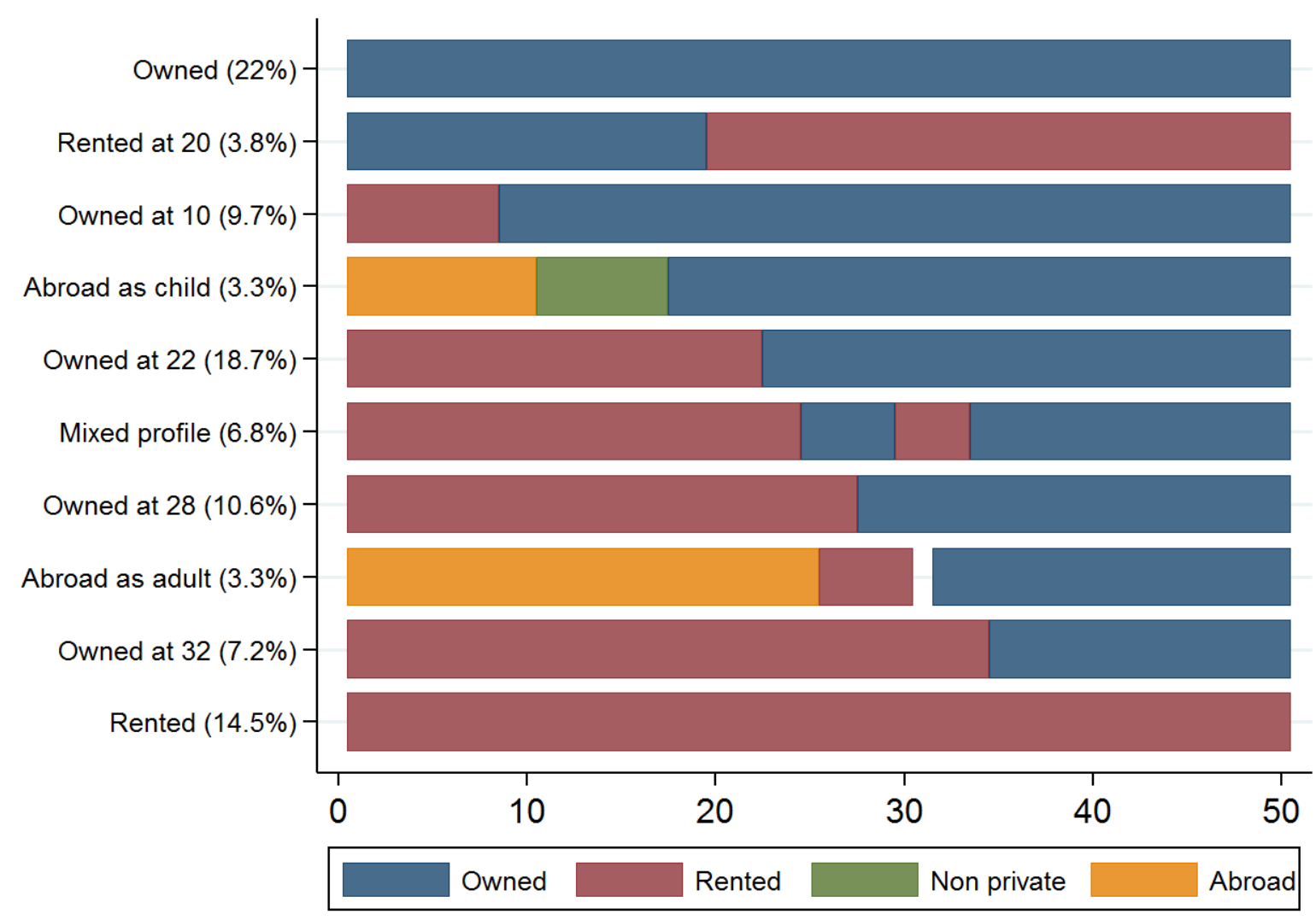

Figure 2. Modalplot of the 10 clusters (proportion of respondents) $(\mathbf{N}=7505)$

\section{Analysis}

Using a series of multivariate regressions, the associations of duration and timing, as well as different types of sequences, with later life wellbeing are examined. We control for age, gender, ethnicity, marital status and health status, and use weights to account for selection of respondents who answered the life history questionnaire (Ward et al., 2009). We consciously do not control for other aspects of socioeconomic position (such as wealth, class or education) for theoretical reasons. Housing careers in our opinion constitute an alternative marker for life course socioeconomic position, in line with current ideas on the multidimensionality of social class (Savage et al., 2013). As housing careers can therefore be correlated, potentially causally related and a part of other measures of social position, we refrain from including them in our analysis, focusing instead on the direct relationship between housing careers and later life wellbeing. Note that the reported coefficients come from separate multivariate models, and as such we are only testing one measure at the time. 


\section{Duration}

Table 5. Unstandardised coeffients in multivariate regression of duration measures on wellbeing, controlling for age, sex, ethnicity, marital status, health status (weighted)

\begin{tabular}{lcccccc}
\hline & \multicolumn{2}{c}{ SWLS (n=6025) } & \multicolumn{2}{c}{ CES-D (n=6926) } & \multicolumn{2}{c}{ CASP (n=5902) } \\
& coef & Se & Coef & Se & Coef & se \\
\hline Ownership & .005 & .006 & $-.011^{* * *}$ & .002 & $.034^{* * *}$ & .006 \\
Renting & -.010 & .006 & $.012^{* * *}$ & .002 & $-.039 * * *$ & .006 \\
Non private & .023 & .020 & -.001 & .006 & .030 & .022 \\
Abroad & .027 & .018 & .003 & .005 & .031 & .017 \\
\hline
\end{tabular}

$* * * \mathrm{p}<0.01, * * \mathrm{p}<0.05, * \mathrm{p}<0.1$

Table 5 shows the associations of duration in a type of housing on different dimensions of wellbeing in later life. It is clear that renting for longer has a negative association with CES-D (emotional wellbeing) and CASP (eudemonic wellbeing) in later life, with SWLS (life satisfaction) showing a weaker, non-significant association. Being an owner for a longer time is associated with fewer depressive symptoms as well as higher eudemonic wellbeing, but not with life satisfaction. Time lived in non-private accommodation or abroad is not significantly associated with later life wellbeing, but there is a suggestion of higher satisfaction and eudemonic wellbeing for those that lived abroad, or in non-private dwellings longer.

\section{Timing}

Table 6. Unstandardised coeffients in multivariate regression of timing measures on wellbeing, controlling for age, sex, ethnicity, marital status, iadl (weighted)

\begin{tabular}{rcccccc}
\hline & \multicolumn{2}{c}{ SWLS (n=6025) } & \multicolumn{2}{c}{ CESD (n=6926) } & \multicolumn{2}{c}{ CASP (n=5902) } \\
& Coef & SE & Coef & SE & Coef & SE \\
\hline Number of & & & & & & \\
moves & & & & & & \\
Childhood & .012 & .087 & -.012 & .027 & .148 & .100 \\
Young Adult & -.062 & .073 & $-.056^{* *}$ & .019 & $.227^{* *}$ & .075 \\
$\quad$ Midlife & $-.326^{* * *}$ & .094 & -.014 & .024 & -.134 & .104 \\
Entropy & & & & & & \\
$\quad$ Childhood & -.086 & .204 & -.002 & .058 & .235 & .229 \\
Young Adult & .080 & .167 & $-.131^{* *}$ & .046 & $.495^{* *}$ & .178 \\
$\quad$ Midlife & $-.827^{* * *}$ & .221 & .051 & .059 & $-.599^{*}$ & .244 \\
Instability & & & & & & \\
$\quad$ Childhood & .640 & 1.057 & -.010 & .331 & 2.205 & 1.218 \\
Young Adult & .891 & .763 & $-.660^{* *}$ & .230 & $2.641^{* *}$ & .858 \\
Midlife & $-4.320^{*}$ & 2.023 & .045 & .543 & -2.616 & 2.386 \\
\hline
\end{tabular}

*** $p<0.01, * * p<0.05, * p<0.1$

The results of the importance of the timing of house moves over life stages (Table 6) are similar over different measures of house moves, but differ by form of later life wellbeing. While satisfaction in later life is negatively associated with more and more diverse house moves in midlife, depressive symptoms and eudemonic wellbeing are associated consistently, respectively negatively and positively, 
with moving more in young adulthood. Moving more or to different types of housing as a young adult is associated with less depressive symptoms and higher eudemonic wellbeing in later life. More changes, or changing to a different type of dwelling in midlife is negatively associated with autonomy in later life. There is no significant association of moving more, or to different types of housing as a child. One caveat in this last finding is that different types of less common non-private types of housing are investigated as one category, so that changes between them are not detected in our instability or entropy measures.

\section{Order}

We examine the extent to which the ten housing career patterns resulting from our optimal matching analysis of the sequence data explain later life wellbeing, controlling for age, gender, ethnicity, marital status and functional health (Figure 3 ). The group that stands out negatively over each of the wellbeing outcomes are those that start to rent at 20, having grown up in owned accommodation.
Buying a house before the age of thirty is associated with better outcomes for all three wellbeing indicators. Those with a mixed profile, who showed on average to return from owned housing to renting in their late twenties, have a similar, lower than average, wellbeing as late buyers. The relation of other housing patterns with wellbeing is more indicator-specific. Lifelong house-owners having an average score in life satisfaction, but markedly fewer depressive symptoms and a higher degree of autonomy in later life. Lifelong renters have an average score on life satisfaction, but stand out as having more depressive symptoms as well as having lower scores on autonomy in later life. Those who grew up abroad, but came to England as a child stand out positively in life satisfaction and autonomy, but not depressive symptoms. People who grew up abroad and came to England as an adult, report average scores of life satisfaction and eudemonic wellbeing, but more depressive symptoms.

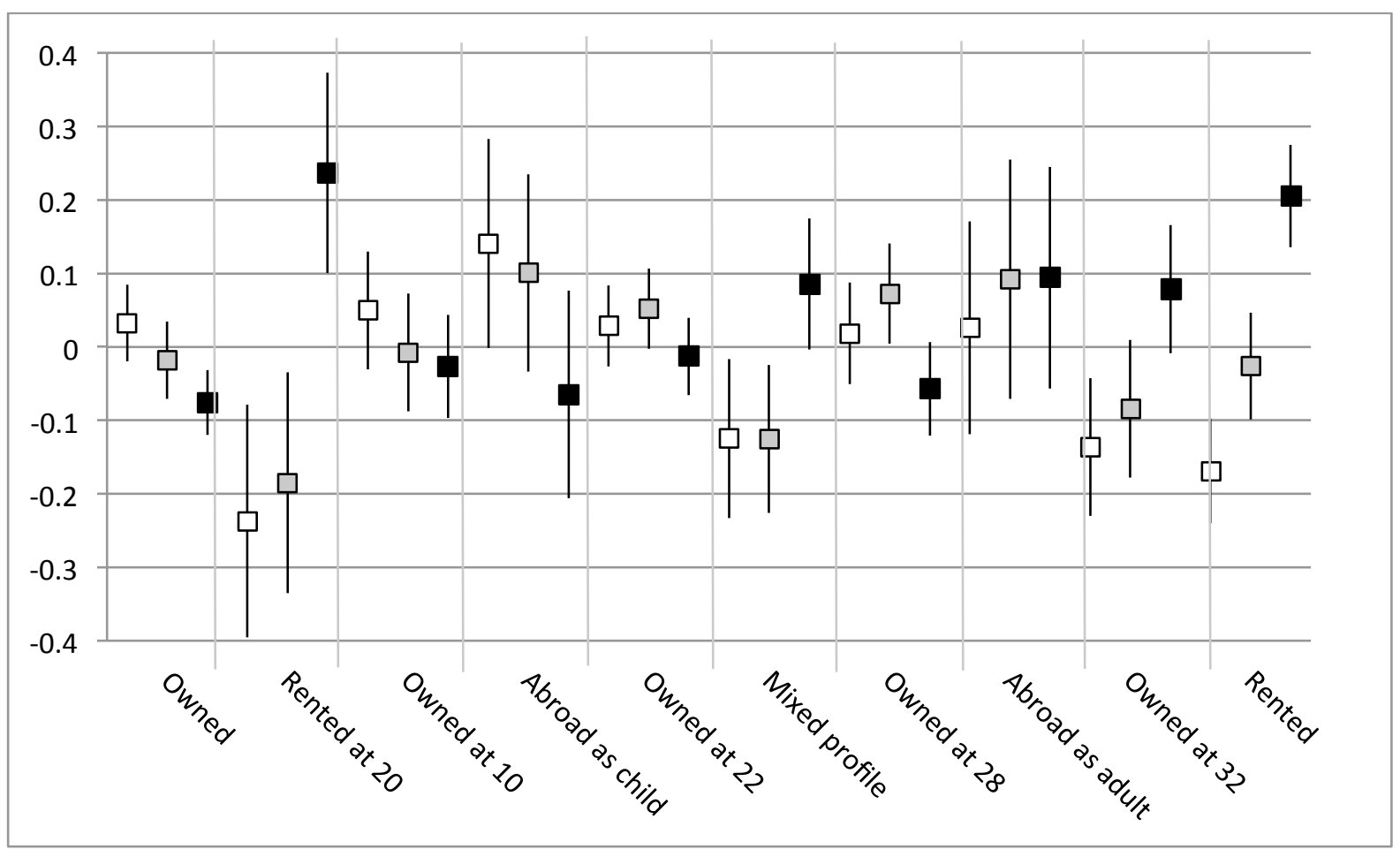

Fig 3: Predicted standardised wellbeing scores CASP (white, $N=5904$ ), SWLS (grey, $N=6027$ ) and CES-D (black, $\mathrm{N}=6928$ ) for 10 housing career clusters, adjusted for age, sex, ethnicity, marital status, iadl (weighted) 


\section{Discussion and conclusions}

This paper examines the potential association of housing careers from birth to the age of 50 with later life wellbeing in England. Housing is a marker of socioeconomic position, being one of the primary forms of wealth accumulation, as well as potentially having more psychosocial effects, as a safe space or source of instability. Informed by life course theory, we distinguish between aspects of duration, timing and order in housing sequences, as empirical measures of respectively accumulation, critical period and mobility. Using the information on housing in the life history data of the English Longitudinal Study of Ageing (ELSA), we use four possible housing states: renting, owning, nonprivate dwelling or living abroad. As later life wellbeing consists of different but related dimensions, we distinguish between affective (CESD), cognitive (SWLS) and eudemonic (CASP) wellbeing.

Duration in a state is a way to translate accumulation of (dis)advantage over the life course. Certain types of housing, such as living in an owned house, exemplify advantage, while others, such as renting, represent disadvantage. By extracting the total cumulative duration in a state from the housing sequences, we illustrated that the more years a person spent in rented housing, the poorer her/his later life affective and eudemonic wellbeing was. Inversely, the longer one lived in owned housing the better later life affective and eudemonic wellbeing was. These findings support our hypothesis, flowing from cumulative (dis)advantage theory, that differences in housing tenure represent differences in housing quality and exposure to risk, which over the long term produce marked differences in quality of life. The quantity of time spent in non-private housing or abroad is not related with later life wellbeing.

The timing of moves is the second aspect of the housing career that we examined. Rather than examining a single move, or moving over the whole housing career, we analysed the associations with later life wellbeing of moving in different life phases. This relates to life course ideas of critical or sensitive periods (although typically only focused on early life) that can scar a person for the rest of her/his life. Our analysis, using three distinct measures of the frequency of moving, found no negative associations with wellbeing of moving more frequently in childhood, in line with other research. This surprising finding supports the idea that moving house is often motivated by a perceived improvement in neighbourhood or housing conditions. The absence of the hypothesised negative side to moving house more often, such as the loss of social resources, which are thought to affect the disadvantaged more than others, can be understood when thinking about the temporal context of the cohorts we are studying. For the bulk of respondents in our study childhood was situated in the period when social housing expanded substantially, in the period around 1960 for the median birth cohort in our study. Social housing in this period was often an improvement from what was available on the private market, detached or semi-detached houses with gardens instead of shared ageing Victorian accommodation. As such it is likely that moving in childhood, even for the more disadvantaged, more often represented an improvement rather than deterioration in living circumstances.

Moving more as a young adult actually was associated negatively with symptoms of depression in later life and positively with eudemonic wellbeing. The positive associations of instability in our opinion mark important life course transitions occurring in this period, such as attending higher education, cohabiting with a partner or having a child, all of which function as important social and economic resources later on in life. Missing out on these transitions can be linked indirectly, through building up less human, social and economic capital as a young adult, to lower later life wellbeing. Satisfaction with life is not related to residential instability as a young adult, but is negatively associated with moving more often in midlife. Major adverse events, such as divorce, loss of spouse, unemployment and disability have shown to have lasting negative effects on subjective wellbeing (Lucas, 2007), and are often associated with moving (Clark, 2016). As negative shocks such as divorce, separation and onset of disability occur more in midlife, we believe this explains the negative association between moving more often in this life stage and lower satisfaction in later life.

The third aspect of the timing of events that this paper examines is order. Does the order of transitions between one housing state and the next matter for later life wellbeing? Conceptually the importance of order is related to social mobility. 
Earlier research has confirmed that upward mobility is positively related with later life health and wellbeing, while downward mobility is negatively associated (Otero-Rodríguez et al., 2011; Vanhoutte \& Nazroo, 2016a). Nevertheless, social mobility might to some extent reflect larger societal changes like the expansion of education or the shift to a service economy, depending on which indicators are used to measure mobility, so that it is useful to examine housing as an alternative indicator of position on the social ladder. Using optimal matching analysis with dynamic hamming to determine distances between sequences, the housing careers were divided into ten identifiable groups. It is clear from our analysis that renting after growing up in an owned house, which is an unambiguously downward form of social mobility, is associated with the lowest levels of later life wellbeing in comparison to other housing careers. This makes clear how essential housing is to wellbeing: no matter what your social origins are, not managing to secure an own home is associated with lower later life wellbeing. The results for upward mobility, or moving from rented to owned housing, are less clear, and strongly depend on the age of transition, with earlier ownership generally related to better later life outcomes.

Investigating order in housing careers through whole sequences allows us to uncover the heterogeneity present in housing careers, and their possible associations with later life wellbeing. To what extent do atypical housing careers, which deviate from the normative transition from renting to home-ownership, relate to either higher or lower wellbeing in later life? How do periods of residence abroad or in non-private dwellings fit in a housing career, and are they related to better or worse later life outcomes? Important to keep in mind in looking at the order of these sequences is that the home is not necessarily owned by the respondent, parents can be owners as well. About a third of the sample did not report change in housing state, continuously being in either rented or owned accommodation. As this study has shown, longer duration of living in either rented or owned accommodation has important implications for later life wellbeing, so it is no surprise that these trajectories are associated with respectively relatively poor and good later life wellbeing, with the exception of life satisfaction, on which duration had no association. Just under half of the sample transitioned from living in rented to owned accommodation, at different ages, as discussed earlier. The remaining share of respondents, about $17 \%$, has atypical life courses. The mixed profile, where living in an owned home is followed by a period of renting, and then again ownership, is associated with lower wellbeing scores in terms of life satisfaction and autonomy. The two remaining atypical trajectories both start off living abroad. One group moves into non-private dwellings (which could be boarding schools) in England around the age of ten, and starts living in an owned home before the age of 20 . The other group lives in rented housing in England in their twenties, and after a relatively short time moves to an owned house. Taking into account the cohorts included in the study, both groups must be seen in the context of the end of empire, coming from privileged backgrounds, which is evident by possible attendance of boarding schools and living in an owned home early. A secondary interpretation is that the latter group, arriving in England as young adults exhibits the typical characteristics of positive selection common among migrants (Borjas, 1989), such as a high motivation as well as better education and health, resulting in a steep and "successful" career. While both groups have a high satisfaction later in life, those who returned as child score high for the other forms of wellbeing, while those who returned as adults have a near average level of autonomy, but strangely have higher than average levels of depressive symptoms.

The methods used in this paper do not allow statistical causal inference, as there is a possibility of reverse causality, common cause or spuriousness due to a confounding variable, next to the possibility that our findings are coincidental or resulting from type I error. Our results nevertheless provide a suggestion of logical causality, because of the low probability of reverse causality on the one hand and the theoretical approach to housing careers as a dimension of social position in its own right. Reverse causality is unlikely due to the earlier temporal occurrence of the housing histories in relation to the measurement of wellbeing. There is a theoretical possibility that people with higher wellbeing retrospectively report more favourable housing histories, but the literature considers retrospective reports using event history questionnaires to be reliable (Belli, 1998), so that this is unlikely. The investigated aspects of housing histories could, partly or entirely, be attributed to a 
latent common cause, i.e. social position, or mediate other measures of social position such as occupational class position, education or wealth. Adopting a conception of class which is multidimensional, and comprises housing as a distinct form of economical capital (Savage et al., 2013), we chose to firmly establish the primary relationship between housing careers and wellbeing, not investigating the interplay between housing careers and other dimensions of class in this study, as multicollinearity between these measures could underestimate the importance of housing careers.

This paper illustrates that different types of wellbeing do not always behave in a similar way. While satisfaction with life tends to reflect what has happened in more recent life stages, depressive symptoms and eudemonic measures of wellbeing reflect experiences across the whole life course. This finding confirms the notion that life satisfaction, due to its cognitive nature, functions as an adaptive, homeostatic system, while affective and eudemonic aspects of wellbeing are more responsive to respectively mental and physical health issues.

Our study suffers some important limitations. Firstly, some respondents did not respond to the life history questionnaire, and although we correct for this using the design weights, the reported proportions of certain less desirable housing careers in the population could be underestimated, or some heterogeneity might not be captured. Secondly, our analysis is based on relatively coarse, and subjective, reports of housing. More detailed information on the value or size of dwellings, as well as social or private renting, was not collected, and several categories were collapsed to non private dwellings. Using more detailed categories made it difficult to impute the gaps, and a more complete sample was chosen over more detailed information. The highlighted associations with tenure could equally be a function of the neighbourhood in which houses are located. Furthermore, as we use retrospective data, we rely on the subjective recollection individuals have of their housing situation. Hybrid housing situations as well as part-time non-private housing therefore are forced into one category, which can lead to underreporting. Thirdly, this study is based on historical data, so that the validity of our findings cannot be straightforwardly extrapolated to younger cohorts and the current period. Furthermore we did not investigate specific cohort or period effects, as this requires a different approach. The possible interplay of housing with other indicators of social position with housing was deliberately left outside the scope of this study, whose contribution lies not only in its focus on housing but in its exploration of the multidimensionality of wellbeing. We hope that future research can address these limitations.

\section{Acknowledgements}

BV and JN were funded by the fRaill project (grant MRC G1001375/1) as part of the cross-research council Life Long Health and Wellbeing Programme. MW was supported by funding from the German Research Foundation (Deutsche Forschungsgemeinschaft), project number: WA 3065/3-1. ELSA was developed by a team of researchers based at the NatCen Social Research, University College London, University of Manchester and the Institute for Fiscal Studies. The data were collected by NatCen Social Research. The funding is provided by the National Institute of Aging in the United States, and a consortium of UK government departments, initially co-ordinated by the Office for National Statistics and more recently by the Economic and Social Research Council. The developers and funders of ELSA and the Archive do not bear any responsibility for the analyses or interpretations presented here.

\section{References}

Abbott, A. (1995). Sequence Analysis: New Methods for Old Ideas. Annual Review of Sociology. https://doi.org/10.1146/annurev.so.21.080195.000521

Abbott, A. (2001). Time matters. On Theory and Method. Chicago: Univeristy of Chicago Press.

Aisenbrey, S., \& Fasang, a. E. (2010). New Life for Old Ideas: The "Second Wave" of Sequence Analysis Bringing the "Course" Back Into the Life Course. Sociological Methods \& Research, 38(3), 420-462. 
https://doi.org/10.1177/0049124109357532

Axinn, W. G., Pearce, L. D., \& Ghimire, D. (1999). Innovations in Life History Calendar Applications. Social Science Research, 28, 243-264. https://doi.org/10.1006/ssre.1998.0641

Banks, J., Blundell, R., \& Smith, J. P. (2012). Understanding Differences in Household Financial Wealth between the United States and Understanding Differences in Household Financial Wealth between the United States and Great Britain.

Belli, R. F. (1998). The structure of autobiographical memory and the event history calendar: Potential improvements in the quality of retrospective reports in surveys. Memory, 6(4), 383-406. https://doi.org/10.1080/741942610

Ben-shlomo, Y., \& Kuh, D. (2002). A life course approach to chronic disease epidemiology: conceptual models , empirical challenges and interdisciplinary perspectives. International Journal of Epidemiology, 31(6), 285-293. https://doi.org/10.1093/intjepid/31.2.285

Blane, D. B., Harding, S., \& Rosato, M. (1999). Does social mobility affect the size of the socioeconomic mortality differential?: evidence from the Office for National Statistics Longitudinal Study. Journal of the Royal Statistical Society. Series A, (Statistics in Society), 162 (Pt. 1), 59-70. https://doi.org/10.1111/1467-985X.00121

Blane, D. B., Higgs, P., Hyde, M., \& Wiggins, R. D. (2004). Life course influences on quality of life in early old age. Social Science \& Medicine (1982), 58(11), 2171-9. https://doi.org/10.1016/j.socscimed.2003.08.028

Borjas, G. J. (1989). Economic Theory and International Migration. International Migration Review, 23(3), 457-485. https://doi.org/10.2307/2546424

Brzinsky-Fay, C., Kohler, U., \& Luniak, M. (2006). Sequence analysis with Stata. Stata Journal, 6(4), 435-460.

Clark, W. A. V. (2016). Life events and moves under duress: disruption in the life course and mobility outcomes. Longitudinal and Life Course Studies, 7(3), 218-239. https://doi.org/10.14301/llcs.v7i3.376

Clark, W. A. V, Deurloo, M. C., \& Dieleman, F. M. (1994). Tenure Changes in the Context of Micro-level Family and Macro-level Economic Shifts. Urban Studies, 31(1), 137-154. https://doi.org/10.1080/00420989420080081

Clark, W. A. V, Deurloo, M. C., \& Dieleman, F. M. (2003a). Housing Careers in the United States , 1968 - 93 : Modelling the Sequencing of Housing States. Urban Studies, 4O(1), 143-160. https://doi.org/10.1080/00420980220080211

Clark, W. A. V, Deurloo, M., \& Dieleman, F. (2003b). Housing Careers in the United States, 1968-93: Modelling the Sequencing of Housing States. Urban Studies, 40(1), 143-160. https://doi.org/10.1080/00420980220080211

Clark, W. A. V, \& Onaka, J. (1983). Life Cycle and Housing Adjustment as Explanations of Residential Mobility. Urban Studies, 20(1), 47-57. https://doi.org/10.1080/713703176

Dannefer, D. (2003). Cumulative advantage/disadvantage and the life course: Cross-fertilizing age and social science theory. The Journals of Gerontology Series B: Social Sciences, 58(6), 327-337. https://doi.org/10.1093/geronb/58.6.5327

Diener, E., Emmons, R., Larsen, R. J., \& Griffin, S. (1985). Satisfaction with life scale. Journal of Personality Assessment, 49(1), 71-75. https://doi.org/10.1207/s15327752jpa4901_13

Diener, E., Suh, E., \& Lucas, R. E. (1999). Subjective well-being: Three decades of progress. Psychological Bulletin, 125(2), 276-302. https://doi.org/10.1037/0033-2909.125.2.276

Dorling, D. (2015). All that is solid. How the great housing disaster defines our times, and what we can do about it. London: Penguin.

Elder, G., Johnson, M., \& Crosnoe, R. (2003). The emergence and development of life course theory. In J. Mortimer \& M. Shanahan (Eds.), Handbook of the life course. (pp. 3-19). New York, NY: Kluwer Academic. https://doi.org/10.1007/978-0-306-48247-2_1

Ellaway, A., \& Macintyre, S. (1998). Does housing tenure predict health in the UK because it exposes people to di erent levels of housing related hazards in the home or its surroundings ? Health \& Place, 4(2), 141-150. https://doi.org/10.1016/S1353-8292(98)00006-9 
Evans, G. W., \& Kantrowitz, E. (2002). Socioeconomic status and health: the potential role of environmental risk exposure. Annual Review of Public Health, 23(Figure 1), 303-31. https://doi.org/10.1146/annurev.publhealth.23.112001.112349

Evans, G. W., Wells, N. M., \& Moch, A. (2003). Housing and mental health: a review of the evidence and a methodological and conceptual critique. Journal of Social Issues, 59(3), 475-500. https://doi.org/10.1111/1540-4560.00074

Feijten, P., \& Mulder, C. H. (2002). The Timing of Household Events and Housing Events in the Netherlands: A Longitudinal Perspective. Housing Studies, 17(5), 773-792. https://doi.org/10.1080/0267303022000009808

Freedman, D., Thronton, A., Camburn, D., Alwin, D., \& Young-DeMarco, L. (1988). The Life History Calendar: A Technique for Collecting Retrospective Data. Sociological Methology, 18, 37-68. https://doi.org/10.2307/271044

Gambaro, L., \& Joshi, H. (2016). Moving home in the early years: what happens to children in the UK? Longitudinal and Life Course Studies, 7(3), 265-287.

Halpin, B. (2014). SADI: Sequence Analysis Tools for Stata (No. WP2014-03). Limerick.

Halpin, B. (2015). Multiple Imputation for Categorical Time-series (No. WP2015-02). Limerick.

Halpin, B. (2016). Cluster analysis stopping rules in Stata (No. WP2016-01).

Hildon, Z., Smith, G., Netuveli, G., \& Blane, D. B. (2008). Understanding adversity and resilience at older ages. Sociology of Health \& IIIness, 30(5), 726-40. https://doi.org/10.1111/j.1467-9566.2008.01087.x

Hiscock, R., Kearns, A., MacIntyre, S., \& Ellaway, A. (2001). Ontological security and psycho-social benefits from the home: Qualitative evidence on issues of tenure. Housing, Theory and Society, 18(1990), 5066.

Hopton, J. L., \& Hunt, S. M. (1996). Housing conditions and mental health in a disadvantaged area in Scotland. Journal of Epidemiology and Community Health, 50(1), 56-61. https://doi.org/10.1136/jech.50.1.56

Hyde, M., Wiggins, R. D., Higgs, P., \& Blane, D. B. (2003). A measure of quality of life in early old age: the theory, development and properties of a needs satisfaction model (CASP-19). Aging \& Mental Health, 7(3), 186-94. https://doi.org/10.1080/1360786031000101157

Jivraj, S., Nazroo, J., Vanhoutte, B., \& Chandola, T. (2014). Aging and Subjective Well-Being in Later Life. The Journals of Gerontology. Series B, Psychological Sciences and Social Sciences, 1-12. https://doi.org/10.1093/geronb/gbu006

Kahneman, D., \& Krueger, A. (2006). Developments in the measurement of subjective well-being. The Journal of Economic ..., 20(1), 3-24. https://doi.org/10.1257/089533006776526030

Kendig, H. L. (1990). A life course perspective on housing attainment. In D. Myers (Ed.), Housing demography: linking demographic structures and housing choices (pp. 133-156). Madison: Univeristy of Wisconsin Press. https://doi.org/10.1136/bmjopen-2013-004476

Kendig, H. L., Byles, J. E., Loughlin, K. O., Nazroo, J. Y., Mishra, G., Noone, J., ... Forder, P. M. (2014). Adapting data collection methods in the Australian Life Histories and Health Survey : a retrospective life course study. BMJ Open, 4, e004476. https://doi.org/10.1007/s12062-015-9138-7

Kendig, H. L., \& Nazroo, J. (2016). Life Course Influences on Inequalities in Later Life : Comparative Perspectives. Journal of Population Ageing, 9(1-2), 1-7.

Kessler, R. C. (1997). THE EFFECTS OF STRESSFUL LIFE EVENTS ON DEPRESSION. Annual Review of Psychology, 48(1), 191-214. https://doi.org/10.1146/annurev.psych.48.1.191

Lesnard, L. (2006). Optimal Matching and Social Sciences: Describing Social Rhythms with Optimal Matching. Paris.

Lucas, R. E. (2007). Adaptation and the Set-Point Model of Subjective Well-Being. Current Directions in Psychological Science, 16, 75-79. https://doi.org/10.1111/j.1467-8721.2007.00479.x

Lupton, R. (2016). The Influence ( $\mathrm{s}$ ) of housing policies on the residential moves of families with young children. Longitudinal and Life Course Studies, 7(3), 288-301. https://doi.org/10.14301/llcs.v7i3.377

Lupton, R., Tunstall, R., Sigle-Rushton, W., Obolenskaya, P., Sabates, R., Meschi, E., ... Salter, E. (2009). Growing up in social housing in Britain: A profile of four generations, 1946 to the present day. 
London.

Macintyre, S., Ellaway, A., Hiscock, R., Kearns, A., Der, G., \& McKay, L. (2003). What features of the home and the area might help to explain observed relationships between housing tenure and health? Evidence from the west of Scotland. Health and Place, 9(3), 207-218. https://doi.org/10.1016/S13538292(02)00040-0

Manzo, L. C., Kleit, R. G., \& Couch, D. (2008). “Moving Three Times Is Like Having Your House on Fire Once”: The Experience of Place and Impending Displacement among Public Housing Residents. Urban Studies, 45(9), 1855-1878. https://doi.org/10.1177/0042098008093381

Marmot, M., Oldfield, Z., Clemens, S., Blake, M., Phelps, A., Nazroo, J., ... Oskala, A. (2017). English Longitudinal Study of Ageing: Waves 0-7, 1998-2015.

Mulder, C. H., \& Wagner, M. (1998). First-time Home-ownership in the Family Life Course : A West German Dutch Comparison. Urban Studies, 35(4), 687-713. https://doi.org/10.1080/0042098984709

Nakazato, N., Schimmack, U., \& Oishi, S. (2011). Effect of Changes in Living Conditions on Well-Being: A Prospective Top-Down Bottom-Up Model. Social Indicators Research, 100(1), 115-135. https://doi.org/10.1007/s11205-010-9607-6

Niedzwiedz, C. L., Katikireddi, S. V, Pell, J. P., \& Mitchell, R. (2012). Life course socio-economic position and quality of life in adulthood: a systematic review of life course models. BMC Public Health, 12(1), 628. https://doi.org/10.1186/1471-2458-12-628

Oishi, S., \& Schimmack, U. (2010). Residential mobility, well-being, and mortality. Journal of Personality and Social Psychology, 98(6), 980-994. https://doi.org/10.1037/a0019389

Otero-Rodríguez, A., León-Muñoz, L. M., Banegas, J. R., Guallar-Castillón, P., Rodríguez-Artalejo, F., \& Regidor, E. (2011). Life-course socioeconomic position and change in quality of life among older adults: evidence for the role of a critical period, accumulation of exposure and social mobility. Journal of Epidemiology and Community Health, 65(11), 964-71. https://doi.org/10.1136/jech.2010.113555

Pavot, W., \& Diener, E. (1993). Review of the satisfaction with life scale. Psychological Assessment, 5(2), 164. https://doi.org/10.1037/1040-3590.5.2.164

Radloff, L. S. (1977). The CES-D Scale: A Self-Report Depression Scale for Research in the General Population. Applied Psychological Measurement, 1(3), 285-401. https://doi.org/10.1177/014662167700100306

Rossi, P., \& Weber, E. (1996). The social benefits of homeownership: Empirical evidence from national surveys. Housing Policy Debate, 7(1), 1-36. https://doi.org/10.1080/10511482.1996.9521212

Ryff, C. D., \& Keyes, C. L. M. (1995). The structure of psychological well-being revisited. Journal of Personality and Social Psychology, 69(4), 719. https://doi.org/10.1037/0022-3514.69.4.719

Savage, M., Devine, F., Cunningham, N., Taylor, M., Li, Y., Hjellbrekke, J., ... Miles, A. (2013). A New Model of Social Class? Findings from the BBC's Great British Class Survey Experiment. Sociology, 47(2), 219250. https://doi.org/10.1177/0038038513481128

Schröder, M. (2011). Retrospective Data Collection in the Survey of Health, Ageing and Retirement in Europe. SHARELIFE Methodology. Mannheim: Mannheim Research Institute for the Economics of Ageing (MEA).

Steptoe, A., Breeze, E., Banks, J., \& Nazroo, J. (2013). Cohort profile: the English Longitudinal Study of Ageing. International Journal of Epidemiology, 42(6), 1640-8. https://doi.org/10.1093/ije/dys168

Stone, J., Evandrou, M., \& Falkingham, J. (2013). The transition to living alone and psychological distress in later life. Age and Ageing, 42(March), 366-372. https://doi.org/10.1093/ageing/aft006

Stovel, K., \& Bolan, M. (2004). Residential Trajectories. Using optimal alignment to reveal the structure of residential mobility. Sociological Methods \& Research, 32(4), 559-598. https://doi.org/10.1177/0049124103262683

Vanhoutte, B. (2014). The Multidimensional Structure of Subjective Well-Being In Later Life. Journal of Population Ageing, 7, 1-20. https://doi.org/10.1007/s12062-014-9092-9

Vanhoutte, B., \& Nazroo, J. (2016a). Life Course Pathways to Later Life Wellbeing: A Comparative Study of the Role of Socio-Economic Position in England and the U.S. Journal of Population Ageing, 9(1), 157177. https://doi.org/10.1007/s12062-015-9127-x 
Vanhoutte, B., \& Nazroo, J. (2016b). Perspective: Life-history data. Public Health Research \& Practice, 26(3), 4-7. https://doi.org/10.17061/phrp2631630

Wahrendorf, M., \& Chandola, T. (2016). A Life Course Perspective on Work Stress and Health. In J. Siegrist \& M. Wahrendorf (Eds.), Work Stress and Health in a Globalized Economy, The model of Effort Reward Imbalance (pp. 43-66). Springer International. https://doi.org/10.1007/978-3-319-32937-6_3

Ward, K., Medina, J., Mo, M., \& Cox, K. (2009). ELSA Wave Three : Life History Interview. A user guide to the data. London.

Windle, G. S., Burholt, V., \& Edwards, R. T. (2006). Housing related difficulties, housing tenure and variations in health status: Evidence from older people in Wales. Health and Place, 12(3), 267-278. https://doi.org/10.1016/j.healthplace.2004.08.010

Wood, A. M., Taylor, P. J., \& Joseph, S. (2010). Does the CES-D measure a continuum from depression to happiness? Comparing substantive and artifactual models. Psychiatry Research, 177(1-2), 120-123. https://doi.org/10.1016/j.psychres.2010.02.003 